\title{
An Introduction to Gas Geological Laws of Coal Mines in China
}

\author{
Jianliang Gao ${ }^{1,2,3}$, Jiangwei Yan ${ }^{1,2,3}$ \\ ${ }^{1}$ The Collaborative Innovation Center of Coal Safety Production of Henan Province \\ Jiaozuo, China \\ ${ }^{2}$ State Key Laboratory Cultivation Base for Gas Geology and Gas Control \\ Jiaozuo, China \\ ${ }^{3}$ Henan Polytechnic University \\ Jiaozuo, China \\ gao@hpu.edu.cn; gisyjw@hpu.edu.cn
}

\section{Extended Abstract}

Since coal-bearing basins and the gas occurrence highly depend on geological structures and their evolution, they are influenced and controlled by geological conditions. Geological conditions of coal-bearing basins in China are complex, therefore the coal seams have great tendency to induce coal and gas outbursts. The gas occurrence rules and the main controlling factors in different coal-bearing strata have great difference because coal-bearing strata are located in different tectonics areas and have experienced different evaluation periods and tectonic intensities.

According to gas occurrence geological tectonic-level-control rule theory, the gas geology research team of Henan Polytechnic University, has drawn gas geological maps including 2,792 coal mines, 173 coal mining district, as well as 22 provinces in China. The following important points have been revealed based on the study of large amount of gas geology information and the geological maps.

1.The gas occurrence in Chinese coal mines can be classified into 10 tectonic control types. These refer to: regional tectonic compress uplift control type, regional tectonic compress tectonic-sedimentary control type, thrust nappe structure control type, orogenic belt push and squeeze effect control type, regional magmatism effect control type, Cratonic lithosphere control type, regional tectonic uplift and denudation control type, regional tectonics extension rift and sedimentary control type, regional hydrogeology effect control type, low rank coal control type.

2.Gas (coalbed methane) occurrence distribution in Chinese coal mines can be divided into 17 zones which have high gas contents or coal and gas outburst tendency and 13 zones where the gas contents are low. The high gas content or coal and gas outburst zones are located at the north margin of North China block, the south margin of North China block, the Eastern Taihang Mountains, etc. The low gas content zones are located at Western Beijing, Western Shandong ProvinceXuzhou-Fengpei-Yongxia coal mining areas, Daxinganling regions and so on.

The study provides support for the macro-planning of countermeasures for gas control and the exploitation of coalbed methane. Moreover, it lays a reliable foundation for exploring the mechanisms of gas occurrence and distribution in mining areas as well as for understanding the mechanisms of coal and gas outbursts.

Keywords: Coal Mine, Gas Geology, Tectonic Control, Gas Occurrence.

\section{References}

[1] J. Ren, J. Huang,C. Jiang, Geotectonic evolution of China. Beijing: Science Press, 1980.

[2] G. Zhai, J. Ning,J. Jin, Plate tectonic evolution and evaluation of oil and gas basins. Beijing: Petroleum Industry Press, 2002.

[3] Z. Zhang, Gas geology. Xuzhou: China University of Mining and Technology Press, 2009.

[4] Z. Zhang, Y. Lin, S. Lu, Distribution characteristics in China coal seam gas. Beijing: Coal Industry Press, 1998.

[5] Y. Cheng, China's regional geological survey. Beijing: Geology Press, 1994.

[6] Y. Zhang, Y. Cao, H, Xie, "Morphological and structural feature of tonic coal," in Proceedings of the $10^{\text {th }}$ international coal conference. Taiyuan: Shanxi Science Press, 1999, pp. 34-38. 